\title{
The interface between Interactive Art and Human-Computer Interaction: Exploring dialogue genres and evaluative practices
}

\author{
Emanuel Felipe Duarte (1) \\ Institute of Computing \\ University of Campinas \\ Campinas, Brazil \\ emanuel.duarte@ic.unicamp.br
}

\author{
Luiz Ernesto Merkle (1) \\ Academic Department of Informatics \\ Federal University of Technology - Paraná \\ Curitiba, Brazil \\ merkle@utfpr.edu.br
}

\author{
M. Cecília C. Baranauskas \\ Institute of Computing \\ University of Campinas \\ Campinas, Brazil \\ cecilia@ic.unicamp.br
}

\begin{abstract}
The mutual efforts of joining art and science have been an important source of innovation in many fields throughout history. In this article, we investigate the relatively common origins, differences, and similarities between the Interactive Art and Human-Computer Interaction (HCI) areas of knowledge. We also investigate what kind of human-computer interactions are sought by artists or emerge in Interactive Art examples, as well as what kind of frameworks, evaluation criteria or methodologies are reported in the literature to support the design and evaluation of Interactive Art. As a result of our analysis of Interactive Art examples found in the literature and beyond, we derived four genres of dialogue that emerge naturally or are stressed by authors: visual, embodied, tangible and social. These genres, albeit not comprehensive, can inspire the design of novel forms of interaction in computational systems with or without artistic intent. Moreover, frameworks, evaluation criteria, and methodologies may allow a cross-pollination between Interactive Art and HCI. While interactive artists may provide novel ways to look at the design and evaluation of interactive systems, these artists may also benefit from appropriating traditional HCI methods, tools, and technologies for new purposes. Lastly, we draw on our findings and learned lessons to outline a research agenda with the main objectives of 1) encouraging Interactive Art research, 2) studying Interactive Art examples, 3) practicing Interactive Art design and evaluation, and 4) designing Interactive Art for all.
\end{abstract}

Index Terms-Art, Science, Interactive Art, Interaction Design, Dialogue Genres, Ubiquitous Computing, Pervasive Computing, Interactive Art Examples, Interactive Art Evaluation

\section{INTRODUCTION}

The articulation of art and science has been an important source of innovation and contributions in many fields throughout history. In the Renaissance, for example, the search for knowledge often led to a blurred line between art and science. The work of Leonardo da Vinci is an exemplary illustration of this interdisciplinarity. According to Wilson [94], throughout Leonardo's many intellectual accomplishments, engineering inventions, and artistic creations, he was also successful in

This study was financially supported by the National Council for Scientific and Technological Development (CNPq) through grant \#306272/2017-2 and by the São Paulo Research Foundation (FAPESP) through grants \#2015/16528-0, \#2015/24300-9 and \#2017/06762-0. This article is an extended version of work published in [38]. incorporating scientific approaches and theory into the practices and reflections of his creative process (e.g., conducting a careful observation of phenomena and developing grounded theories of understanding). There were no gulfs among the aesthetic, scientific, and technological dimensions of his works or accomplishments, they intermingle each other.

Around four centuries after Leonardo da Vinci, during the late eighteenth hundreds and early twentieth century, both science and art were revolutionary. Science had revolutionary breakthroughs that still shape contemporary research. Einstein's relativity, Heisenberg's quantum mechanics, and Gödel's incompleteness theorems challenged the universal worldview, showing it contingent to the point of view. Art, on the other hand, broke conventions about perspective, representation, the role of the self and the unconscious, starting movements that still influence contemporary artists. Some examples, among a myriad of other ones, are: modernism challenged perspective and classical rules of composition; cubism questioned the solidity of objects and explored relativistic concepts of time; dadaism brought everyday objects to the artistic scene, questioning art itself.

According to Wilson [93], artistic traditions such as iconoclasm (constantly challenging or rejecting the status quo) and a greater appreciation of subjectivity allows artists to be more likely to pursue lines of inquiry devalued by others. By applying these artistic traditions in scientific research projects, it may allow scientific discoveries that would otherwise probably not happen or be overlooked. Furthermore, the author argues that through a closer relationship between artists and scientists, artists may be able to employ their critical thought and become an active part of the creation of new technologies.

Still on the subject of articulating art and science, John Maeda [75] argues that "For those of us involved in either field today [art and science] (and many of us have a hand in both), we know that the similarities between how artists and scientists work far outweigh their stereotypical differences". However, there is also a growing need to better specify what is meant by "art" and "science". Candy and Edmonds, for instance, open the first chapter of Explorations in Art and 
Technology [19] with an epigraph from Roy Ascott, an artist with a long-standing contribution to the relation between the arts and computing, which says "It is no longer enough to speak of the convergence or reciprocity of art and science $[\ldots]$ but to specify which art and which science, and, by what means they might fruitfully interact." [19, p. 4].

In this article, we explore the subject of articulating art and science under the lens of Interaction Design in the HumanComputer Interaction (HCI) and Interactive Art fields. Both $\mathrm{HCI}$ and the Interactive Arts are broad, diversified, and relatively recent fields. They subsume interdisciplinary practices and perspectives. HCI includes computing, among other fields such as psychology, anthropology, language studies, philosophy, communication. The Interactive Arts, in turn, relaxed the compulsory roles attributed to other stakeholders, such as the audience, bringing them to the forefront of the processes of artmaking. Early examples of the explorations of computations in the arts are the Cybernetic Serendipity exhibition held at the Institute for Contemporary Art in London in 1968 [19, p. 5], and Giorgio Moscati and Waldemar Cordeiro's works, who explored computers and printers in the 1960s [77].

Edmonds [45] stresses that some artists give great importance to what the audience feels or the ways it responds. Moreover, in Interactive Art, in particular, experience and participation are not only important but key aspects. Similarly, participation and experience, and shifts in their understanding are also challenging and often enriching what the HCI community conceives as encompassing "User Experience (UX)" design. Benford et al.'s "Uncomfortable UX" concept [9], for instance, employs an annoying form of interaction as a strategy to deliver entertaining, enlightening and socially bonding cultural experiences. Therefore, the articulation between art and science in HCI should be further encouraged, and this may be accomplished through the study and practice of Interactive Art. Weiley and Edmonds [92], for example, argue that HCI researchers can incorporate art approaches to (1) make some types of decisions more explicit by documenting not only results but also the ideation process, (2) support stronger hypothesis generation by fostering divergent thinking and informed intuition, and (3) enrich evaluation methods by adopting a more reflective practice. Furthermore, Edmonds [42] argue that HCI researchers, especially those interested in experience design, could benefit from incorporating the concerns of interactive artists (e.g., hedonic qualities and different forms of engagement) into the study of interaction design and user engagement.

In this article, we present a brief and modest introduction to the intersection between the Interactive Arts and HCI, as well as some examples and criteria of evaluation of interactive works. We revisit the concept of Interactive Art grounded on our Interaction Design perspectives and practices. We bring a subset of the material production of joint efforts between HCI and the Interactive Arts, to reflect on their design processes, following the two main questions:

1) What kinds of human-computer interactions are sought by artists or emerge in Interactive Art examples in the literature and other non-academic sources?

2) What kinds of frameworks, evaluation criteria or methodologies are reported in the literature to support the design and evaluation of Interactive Art?

This article is structured as follows: we begin Section II by presenting a brief background on the connection between Interactive Art and HCI. In Section III we present an initial categorization of dialogue genres from Interactive Art examples found in the literature and other non-academic sources (Question 1). Then, in Section IV we explore different frameworks and methodologies found in the literature that support the design and evaluation of interactive works of art (Question 2). Afterward, in Section V we discuss our main findings and contributions, as well as their implications for the design processes, leading to the outline of a research agenda. Lastly, in Section VI we summarize our main considerations and present directions for further work.

\section{BACKGROUND}

The cross-pollination between the arts and HCI is not new, as some knowledge and methods related to art have been used in HCI for quite some time. For example, Gestalt psychology, color theory, and other visual principles have been applied with relative success in the design of interfaces, bringing visual balance, consistency and harmony, when desired or employed. Furthermore, the methodology described by Frayling as Research through Art and Design [55] has been gaining attention within the HCI community in recent years [7], [58], [96]. Among many possible approaches to understand and articulate art and science through computational works of art, in this article, we focus on something that has been inhabiting the worlds of the arts, the sciences and the technologies for some decades, but somehow always manages to reinvent itself and retains a feeling of novelty and innovation: the theory and practice of Interactive Art itself.

It is worth noting that interactivity in art does not necessarily involve computational technology. According to Muller et al. [78], the act of "experimenting" any kind of work of art is always an active and fundamentally an interactive process. In this case, the interaction occurs in the processes of perception and creation of meaning by the audience. For instance, Hélio Oiticica and Lygia Clark, Brazilian artists, are recognized as rather important to the initial development of the field of Interactive Art, with artworks developed between the 1950s and 1970s. These early works are valuable in their pioneering and other aesthetic qualities.

As argued by According to Muller et al. [78], it was the advent of art which explored computer-based interactivity, material-wise, that brought forth what is now broadly recognized as Interactive Art. Therefore, due to our field of inquiry being HCI, for practical reasons we consider interactivity in art that does not involve computers to be beyond the scope of this article. Furthermore, considering the way our investigation is focused on HCI and Interaction Design, in this article we consider Interactive Art to be any form of art enhanced with computer-based interactivity. It is important, however, to 
emphasize that it is not our intention to define what is and what is not Interactive Art. Even though we give some examples in the next section to suit our needs, we encourage readers to explore the concept of Interactive Art to construct their own understanding of what is (and what is not) Interactive Art.

In Interactive Art, interactivity is not restricted to the cognitive, narrowly understood as within the realm of the mind, the symbolic. It engulfs and demands and includes the embodied, the situated, the historical throughout its frameworks of understanding. It ceases to be conceived solely as a mental abstract process, which would happen in the mind of each spectator. Contrastingly, each participant handles the work of art, in a two-way embodied and intentional sensorymotor-mindful exchange, forming an interactive dialogue that has the potential to be unique for each person.

England [47] points out that Interactive Art and HCI share common origins. During the 1960s and 1970s, several artists explored video and computing technology and created the first digital interactive experiences. Krueger's GLOWFLOW and VIDEOPLACE projects [71], for instance, date from 1969 and 1974 respectively. In Brazil, Waldemar Cordeiro [74], worked in the same period, but also added political-social commentary during the controversial years of the Brazilian military government. Regarding fundamental differences, Edmonds [45] discusses the way Interactive Art is not exactly concerned with task analysis, error prevention or task completion times, recurrent themes in mainstream HCI. Goals may not be well defined, and the focus tends to be on pleasure, play, experience, and engagement. The works of Dunne and Raby [40], which mingle art, design, and computing, are examples of design not for efficiency or usability, but as a catalyst for "design fiction" or "social dreaming". As the authors say, designers can aspire for more than making technology easy to use and consumable.

Though Interactive Art was already on track during the 1960s, the field of computing was still emerging and in process of consolidation as a recognized academic field. Engelbart developed the computer mouse during that decade and published his "Augmenting Human Intellect: A Conceptual Framework" [46] already in 1962. At the Association for Computing Machinery (ACM), people interested in computing and people gathered within the Special Interest Group on Social and Behavioral Computing, renamed as Special Interest Group on Computer-Human Interaction in 1982. Xerox Alto, which is considered the first computational machine designed to embed an operating system and a graphical user interface had its first unities delivered in 1973.

These common interests and themes among interactive artists and interface professionals and researchers, however, fade out during the 1980s, when HCI was formalized as an academic field, and somehow restricted its interests mainly to professionals from areas such as cognitive psychology and computing as its predominant voices. People with other interests went elsewhere because there was no substantial space for more subjective or social aspects of interaction. Later, HCI has seen the sprout and growth of distinct trends or schools, sometimes described as waves. They differ among commentators. Based on Duarte and Baranauskas [36], they can be described roughly as:

1) First-wave $\mathrm{HCI}$ is more concerned with ergonomic universals, task modeling, and experimental methods. It relies heavily on task analysis, cognitivism and information processing models of human behavior. Its methods focus on how subjects, usually in laboratory conditions, process information displayed by a computer and communicate back through a user interface, making use of both experimental methods and more naturalistic inquiries to derive "universal laws", such as Fitt's law [54], Card, Newell and Moran's GOMS [21], and Norman's gulfs of evaluation and execution [80].

2) Second-wave HCI stems from the so-called cognitive science revolution. Around the mid-1980s, divergent researchers and movements questioned the universal validity of such generalizations commonly found in firstwave HCI. Authors such as Winograd and Flores stated the situated, historical, and mediated nature of human cognition [95]. Other examples are Suchman's work on planning and action [88], as well as Bødker's work on human activity [11]. However, the context was still mostly circumscribed around the work environment.

3) Third-wave HCI brings forth previously underrecognized and marginalized topics such as culture and values. As computing reached out [59] across a manifold of human endeavors, affecting the everyday life of a significant parcel of the privileged population, a richer set of phenomena fell under the umbrella of HCI, transcending work in uncountable ways. As such, thirdwave HCI concerns go beyond production-related and "purposeful" tasks (e.g., to study how to reintroduce humanities in HCI to stimulate emancipatory or social change-oriented approaches [6]). It relies on experimental methods and more naturalistic inquiries to understand different facets of everyday life.

According to England [47], since the first years of the 2000s, a community effort was made to bring HCI and art closer together. This is illustrated by panels \& Special Interest Groups (SIGs) (e.g., [49], [51], [85]) and workshops $\&$ art exhibitions (e.g., [1], [48], [50]), mainly at the CHI conference, but there are also contributions in smaller, but no less important conferences, such as Creativity \& Cognition [18]. Without exhausting the subject, there have been academic discussions regarding hybrid evaluation methods that can potentially contribute both to new media arts and HCI practitioners [1]; cataloging the digital arts and reported curatorship experiences [48], [50], [51]; possible articulations of lines of research in digital arts and HCI through intersections and cross-fertilization [49], [53], [85]; the relationships between the Interactive Arts, audience engagement and experience design [43]; how can HCI research be aligned with socially engaged arts practices that encourage debate around societal challenges [26]; how art and HCI discourses can both inform 
and be informed by innovation policies and initiatives [52]; and how art and HCI can investigate together the shifting role of the former "user", who can now become, for instance, an author, collaborator or performer [73].

With the growing number of contributions at the intersection between art and HCI, it is our understanding that interaction designers could benefit from the unconventional thinking and the creative efforts that arise from the creation of Interactive Art in its many forms. This can be achieved by studying dialogue genres found in Interactive Art examples, both in scientific literature and other sources, as well as design and evaluation approaches employed in the creation of Interactive Art artifacts, as we will present in the two following sections.

\section{INTERACTIVE ART: EXAMPLES}

Interactive Art is well covered by the academic literature, as well as within online communities. In this section, we bring some examples of Interactive Art. Our aim in choosing this subset is to illustrate both distinct trends we identified within the literature and the possibility of analyzing the crossfertilization between HCI and the arts. By analyzing examples of interactive works of art from the perspective of both art and computing, we derived some types of emphasis they stressed, mostly based on the genre of dialogue they enable or stress when handled. A dialogue genre is defined at the SIGCHI Curricula for HCI [61] as "the conceptual uses to which the technical means are put.". The identified genres are (A) Visual, (B) Embodied, (C) Tangible, and (D) Social.

Our focus on the dialogue genre or theme of the artifacts restricts the kind of analysis we carry and is somehow naïve, from the perspective of the cultural, situated, and historical dimensions of the artworks we picked. However, though limited, they have enabled us to illustrate the types of technological environments works of art have been exploring, the means they explore, and some of their uses. In the following subsections, we present these four dialogue genres and provide examples to illustrate them.

\section{A. The visual dialogue genre}

People gaze, view and look at Graphical User Interfaces (GUIs), interactive artworks and installations. An interface where the visual is predominant is an example of a visual HCI dialogue genre. GUIs usually stressed the visual representation of something, such as an environment, a landscape, a map, a product, in two or three dimensions. The desktop metaphor enables users to tackle with distinct documents, and later on, as windows, representing distinct applications. As computers and associated displays became cheaper and more affordable, smaller (to be used in headsets) and larger (to engulf us), they enable users to fall in an environment, where we can look, view and sail around, either to design products (computer-aided design and manufacturing) or institutions (virtual museums, digital libraries), or large and complex data sets (geographical information systems).

When stressing the visual interaction qualities or perceptions, the artwork has been sometimes labeled as virtual (i.e., have a digital representation). In many cases, it is experienced through a set of display screens or a virtual reality headset, usually correlated eye tracking or head position, together with more traditional input devices, such as a mouse, keyboard, touchscreen, or joystick.) Usually, these artifacts are designed with a significant degree of aesthetic interest when compared to everyday counterparts. Some examples of Interactive Art with a focus on visual interactions are:

- Live Writing: Gloomy Streets ${ }^{1}$, illustrated in Figure 1a and created by Sang Won Lee, is an application in which the experience of writing a poem is enriched with a real-time audio-visual performance on top of what was written. As a person writes in a blank screen with a typeface and sound effects, which resemble those of a typewriter, the text may start to blur and ripple while an enigmatic sound effect plays in the background. The writer's own emotions emerge through keystrokes and letters that seem to be alive [72].

- Journey ${ }^{2}$, illustrated in Figure $1 \mathrm{~b}$ and developed by thatgamecompany, is originally a Playstation 3 digital game in which the player controls a character roaming in a vast desert towards a distant mountain. Although it is an online multiplayer game, the player has limited interaction with other players, relying only on communication through character movement and a musical chime. It was not the gameplay that made it very well received by both critics and players alike, but the strong emotional and aesthetic experience, as can be seen in the aggregated reviews available at Metacritic ${ }^{3}$ [90].

- Additional examples of visual interaction include but are not limited to: This Is Not Private [32], idMirror [64], and Fukushima Audio Census [69].

\section{B. The embodied dialogue genre}

People are present, move and wander in physically immersive interactive artworks and installations. An interface where the embodiment is predominant is an example of an embodied HCI dialogue genre. As a wide range of sensors and computer vision algorithms are created, become more efficient, affordable and easier to use, computing artifacts became more diluted and distributed across and around the user's physical space (a trend labeled as ubiquitous or pervasive computing). These ubiquitous or pervasive computational technologies can surround the places we live and work in, and embodied computer interfaces enable us to interact with them by being within a physical environment, present with our full bodies.

When stressing or incorporating embodied interactions, the artwork reaches out to the physical world to receive embodied methods of input that go beyond traditional everyday interaction. Usually, it involves sensors capable of identifying psychophysiological indicators, and the person's own body is used for conscious, or even unconscious, interaction with the artwork,

\footnotetext{
${ }^{1}$ Live Writing: Gloomy Streets, by Sang Won Lee https://livewriting.github. io/

2 Journey, by thatgamecompany http://thatgamecompany.com/journey/

${ }^{3}$ http://metacritic.com/game/playstation-3/journey
} 


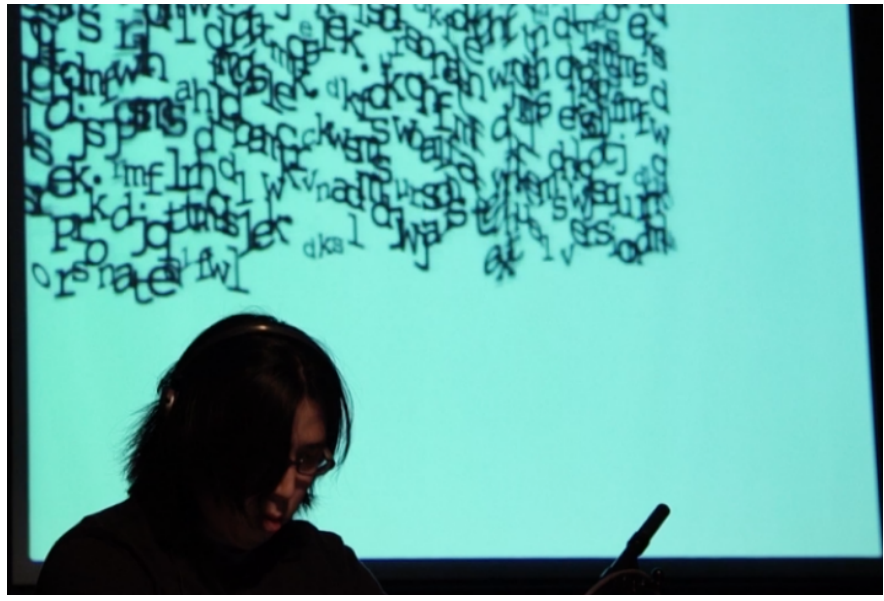

(a) Live Writing: Gloomy Streets [72, p. 1389].

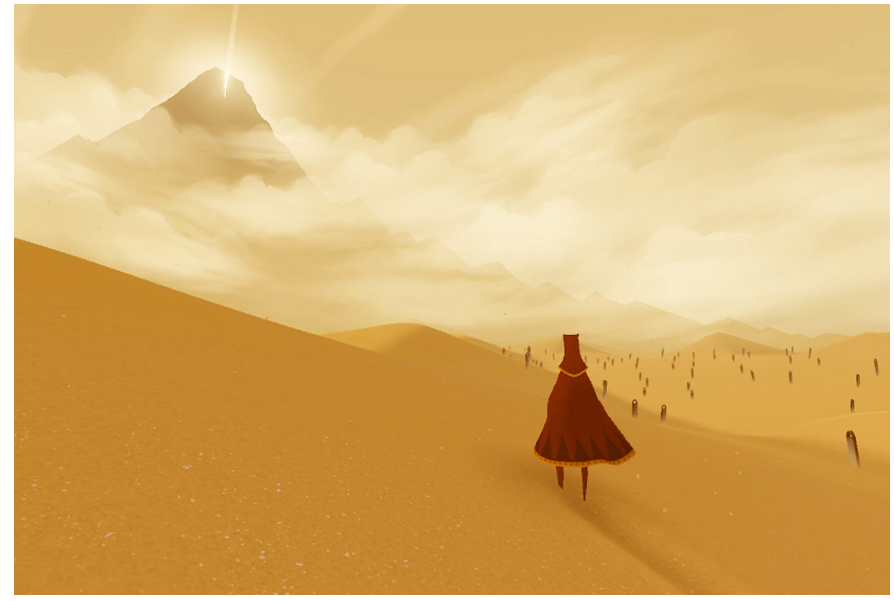

(b) Journey [90] (PlayStation Europe, CC BY-NC 2.0).

Figure 1: Visual dialogue genre examples.

as in the concept of an Enactive System proposed by Kaipainen et al. [66], drawing upon the enactive approach proposed by Varela et al. [91]. Some examples of Interactive Art with a focus on embodied interaction are:

- iMorphia ${ }^{4}$, illustrated in Figure $2 \mathrm{a}$ and created by Richard Brown, is an art installation in which a person has its body tracked by sensors so that a computer connected to a projector can project a virtual character over the person's body. Body tracking allows the projected character to follow the person's movements in real-time. It can be used, for instance, to project fictional characters such as anime or cartoon protagonists, allowing the tracked person to physically impersonate the character, challenging basic conventions of screen-based interaction [14].

- $\mathrm{CAVE}^{5}$, illustrated in Figure $2 \mathrm{~b}$ and created by Domingues et al., is an art installation in which the audience can experience an interactive ritual related to Afro-Brazilian popular religions. Sensors are used to detect physiological indicators and walking patterns to, accordingly, control projections on the walls and other interactive resources, such as ambient sound. The goal is to "enhance the sensorial experiences and amplify kinesthesia by adding the sensations that are formed in response to the physical world, which aesthetically constitutes the principle of synaesthesia" [34, p. 1].

- Additional examples of embodied interaction include but are not limited to: Distractions [15], Avian Attractor [35], and BrightHearts [68].

\section{The tangible dialogue genre}

People touch, handle and manipulate tangible interactive artworks and installations. An interface where tangibility is predominant is an example of a tangible HCI dialogue genre. As interactive devices transcended the graphical output

\footnotetext{
4 iMorphia, by Richard Brown http://mimetics.com/

5 CAVE, by Diana Domingues et al. [34]
}

(representation or spectacle) and computational technology is somehow embedded into physical objects, they enable a person to physically handle these objects. This physical handling has immediate feedback, be it haptic or not, and provide an improved sense of being-in-a-world. This improved sense of being-in-a-world effect, in turn, is not only abstract but concrete, as tangible interfaces enable the manipulation and use of physical tools that are ready-to-hand, enabling a richer set and sense of attitudes and actions contained within these tangible computational objects.

Drawing from the concept of "Tangible Bits" by Ishii and Ullmer [62], in the tangible interaction approach, the interactive works of art go beyond the virtual and is somehow embedded in real-world objects, by enabling their manipulation. It usually involves sensors capable of tracking these objects and sensors in the objects themselves to capture interaction data, as well as actuators that constraint or facilitate the manipulation. They may also involve networked and distributed devices commonly known as Internet of Things (IoT). Some examples of Interactive Art with a focus on tangible interaction are:

- Crafted Logic ${ }^{6}$, illustrated in Figure 3a and created by Irene Posch and Ebru Kurbak, is an interactive installation situated within a larger project focused on handcrafting simple electronic components from scratch. It consists of handcrafted hardware created with textile-crafting techniques, such as crochet. The hardware is connected forming basic logic gates controlled through electromagnetism and can perform designed logical operations. According to the authors, this installation "[...] challenges the aesthetics, interactions, and technology creation scenarios we take for granted in the field today" [83, p. 3884].

- Breaking AndyWall ${ }^{7}$, illustrated in Figure $3 \mathrm{~b}$ and created

${ }^{6}$ Crafted Logic, by Irene Posch and Ebru Kurbak http://www.ireneposch.net/ crafted-logic/

7 Breaking AndyWall, by Leo Kang http://leokang.com/portfolio/index.php/ hciart/breaking-andywall/ 


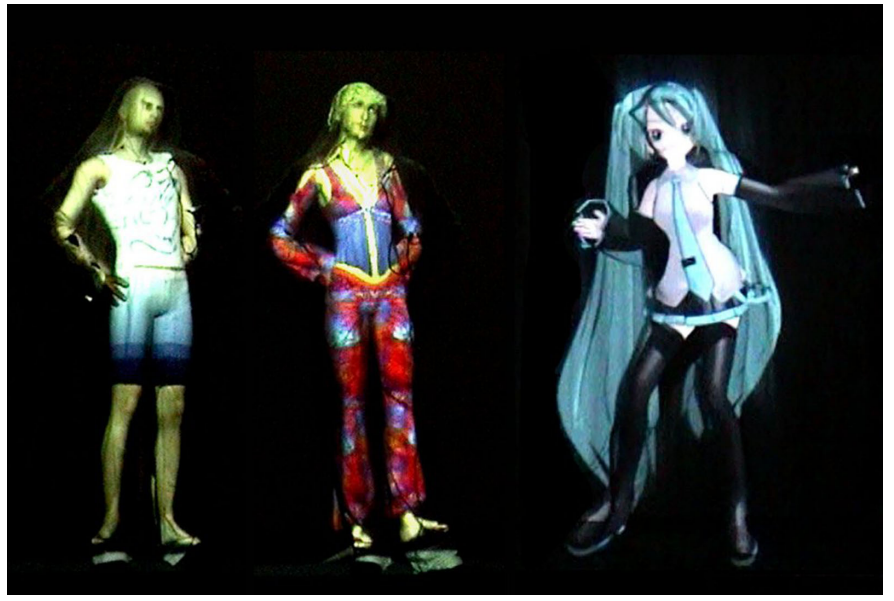

(a) iMorphia [14] (Art.CHI 2016 Archive).

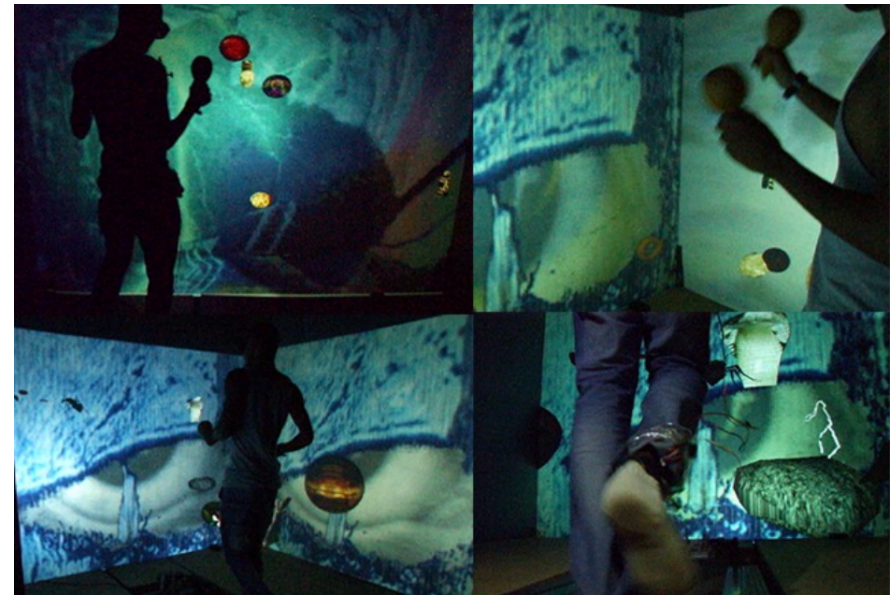

(b) CAVE [34].

Figure 2: Embodied dialogue genre examples.

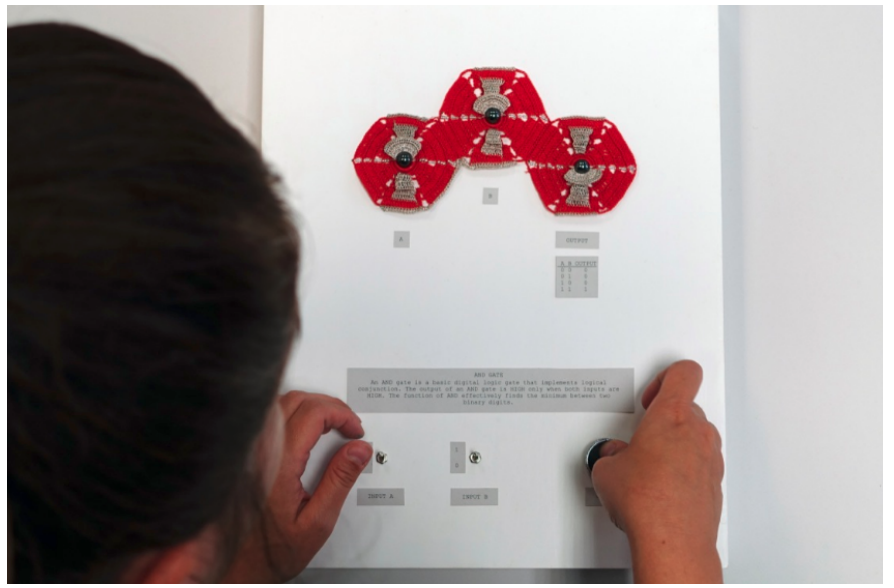

(a) Crafted Logic [83].
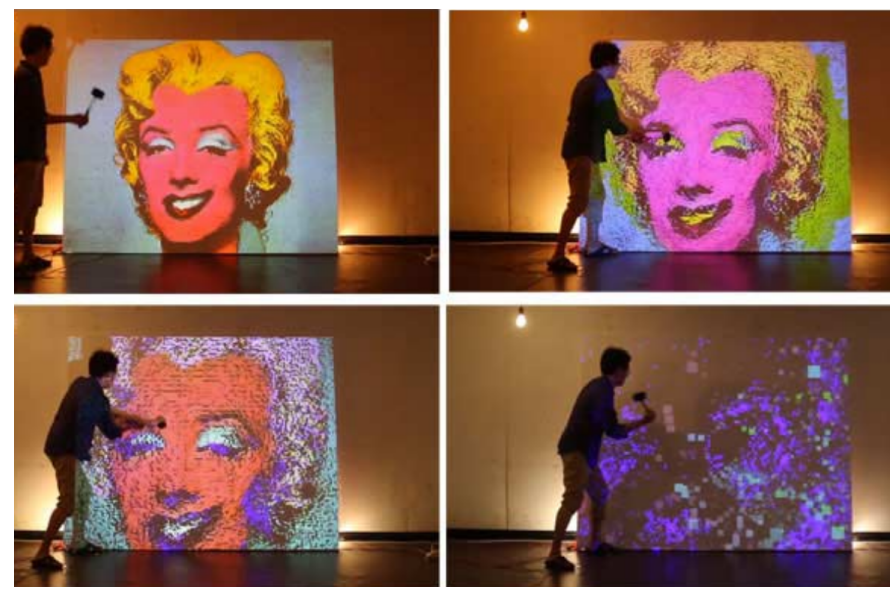

(b) Breaking AndyWall [67].

Figure 3: Tangible dialogue genre examples.

by Leo Kang, is an interactive installation where participants are invited to "destroy" pieces of art that are socially considered what the author calls "great art", such as Andy Warhol's Marilyn Diptych. The chosen famous artwork is projected onto a canvas that can be hit by the audience with a provided wooden hammer. Sound sensors capture the impact of the hammer on the canvas, and with each hit, the projected artwork is gradually broken down into shattered pixels. According to the author, the objective is to provide an experimental space to discuss the dynamic roles of users in art and Design [67].

- Additional examples of tangible interaction include but are not limited to: Endless Ripples [60], eBee [82], and Dichroic Wade [84].

\section{The social dialogue genre}

People share, communicate and dialog within social interactive artworks and installations. An interface where the social is predominant is an example of a social HCI dialogue genre. As computer networks continuously connect privileged people in separated geographical and social landscapes, the sharing, collective, and participatory nature of knowledge are also constantly targeted. This happens not only computationally, but also culturally, politically, and historically. When some social or geographical and spatial boundaries become obsolete through computational technology such as social networks, people with similar or complementary knowledge and skills can create large groups (or, sometimes, "bubbles") to share stories, be part of something bigger, and collaborate or compete among each other.

When stressing or incorporating some kind of social interaction, an artwork may not necessarily excel in its degree of aesthetic interest and neither provide any novel form of interaction with computational technology in the traditional sense; on the other hand, they may somehow allow and/or 
encourage people to interact with each other in unconventional ways through its provided resources. They may encourage people to collaborate and achieve highly complex levels of self-organization. Some examples of Interactive Art with a focus on social interaction are:

- Twitch Plays Pokémon ${ }^{8}$ is a social experiment created by an anonymous programmer, still active by the time we write this article. Its most memorable moment was during the very beginning of February 2014, when thousands of players could simultaneously issue commands to control the character of a live stream play-through of the classic game Pokémon Red [57], as illustrated in Figure 4a. Oscillating between democracy and anarchy, ultimately the players could collaborate to the extent that they surprisingly were able to finish the game in precisely 16 days, 9 hours, 55 minutes and 4 seconds.

- Reddit's /r/place ${ }^{9}$ is a social experiment by the Reddit social network conducted in April 2017. Users of Reddit, also known as Redditors, were given a shared empty canvas with $1000 \times 1000$ pixels, and each Redditor could place or paint only one pixel on the canvas every 5 to 20 minutes. The experiment, illustrated in Figure 4b, lasted only three days, but it was enough to show a fierce competition between different groups of people for the limited pixels, as well as complex levels of self-organization and collaboration between people with shared interests. As an attempt to catalog everything that was created during the three days of the Reddit's /r/place event, the /r/place Atlas ${ }^{10}$ has 1493 entries.

- Additional examples of social interaction include but are not limited to: Tango Apart: Moving Together [44], Whorl [76], and Sprung! [28].

Concerning common interests of HCI and Interactive Art, both assume many forms and can be analyzed from many perspectives, beyond the limited scope of the analysis of this article. Our proposed categorization of dialogue genres and respective examples illustrate only some of these angles. Besides the humanistic value that may or may not be intended, these examples provide a basis to understand further research on important topics for both HCI and Interactive Art. The provided examples encompass, for instance, properties that led to high levels of immersion and engagement; novel forms of interaction with computer systems based on alternative technologies and sensors; and social behaviors of collaboration (or competition) and self-organization through computer systems.

It is important to emphasize that these different dialogue genres are not mutually exclusive, and they are not intended as a strict nor comprehensive categorization of Interactive Art. The Twitch Plays Pokémon and Reddit's /r/place examples, for instance, could also be considered examples of visual dialogue genres due to their computer screen emphasis and interaction

\footnotetext{
8 Twitch Plays Pokémon, anonymous https://twitch.tv/twitchplayspokemon

9 Reddit's /r/place, by Reddit https://www.reddit.com/r/place/

${ }^{10} \mathrm{https}: / /$ draemm.li/various/place-atlas/
}

through traditional peripherals, while embodied and tangible genres can easily become intertwined.

\section{Interactive ART: Design AND EVAluation}

Bannon and Ehn [4] and Kostakos [70] argue that HCI communities often focus on results, products, and services, while the design processes and practices often lack thorough presentation and discussion. However, besides analyzing Interactive Art examples, we may also benefit from studying how these artifacts are created. In this section, we aim to address our second research question, concerning how to evaluate joint HCI and Interactive Art efforts. We briefly present some methods and frameworks that we have considered relevant during our study, without exhausting the subject. We will emphasize evaluation processes, as it is one of the central aspects of HCI practice and research. The evaluation also often informs design in a formative manner.

Evaluation processes in HCI can significantly differ from one another as they have different criteria regarding distinct interests, values, objectives, and methodologies from researchers and practitioners. Leaning on a summary of the three $\mathrm{HCI}$ waves previously presented in Section II, we have:

1) First-wave HCI evaluative criteria appear to be more concerned with finding ergonomic universals and quantifying interaction metrics, relying on experimental methods. They are focused on tasks and intend to improve the fit between human and machine to avoid human error, improve performance, and reduce strain. They are usually conducted in controlled laboratory conditions.

2) Second-wave HCI evaluative criteria are also focused on improving production in work-related activities. However, they go beyond short-term tasks, focusing on longterm human action or work, as well as their outcomes. They are usually carried out in work settings. It is usually conducted in contextualized actual work settings.

3) Third-wave HCI evaluative criteria rely on both experimental methods and more naturalistic inquiries to understand different facets of life and reality. They are mostly conducted in everyday life conditions and way beyond restricted, work-related environments.

In summary, evaluation criteria in HCI spans from shortterm controllable settings, all the way to long-term uncontrollable situations. On the one hand, short-term controllable settings enable some generalization, such as production metrics in the evaluation of a simulated workstation on a shop floor. On the other hand, long-term uncontrollable situations, are more subjective and unpredictable, such as the more naturalistic study of any kind of life activity, not necessarily work-related.

In art, in turn, reception and evaluation tend to be uncontrollable, as in third-wave HCI. Candy [17] argues that evaluation is usually an unfamiliar practice, and sometimes even a rejected notion among artists - even though some form of evaluation may implicitly occur in the art-related activities of critique and curatorship. According to the author, however, there are pioneer practitioners and researchers that are exploring forms of evaluation that impact how art is made 

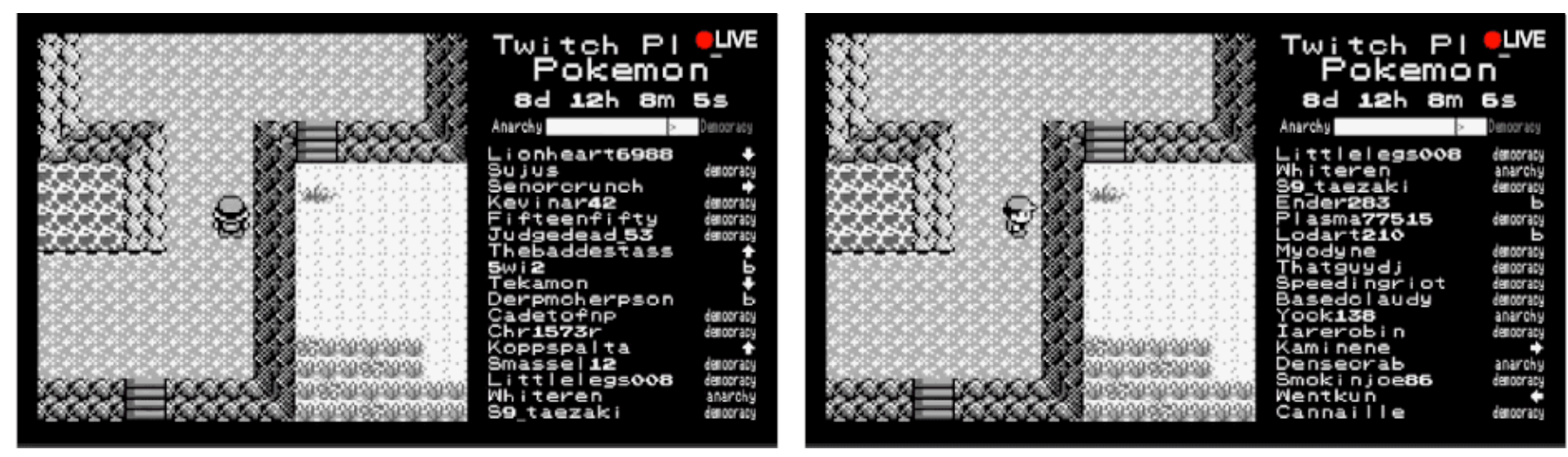

(a) Snapshots of Twitch Plays Pokémon.
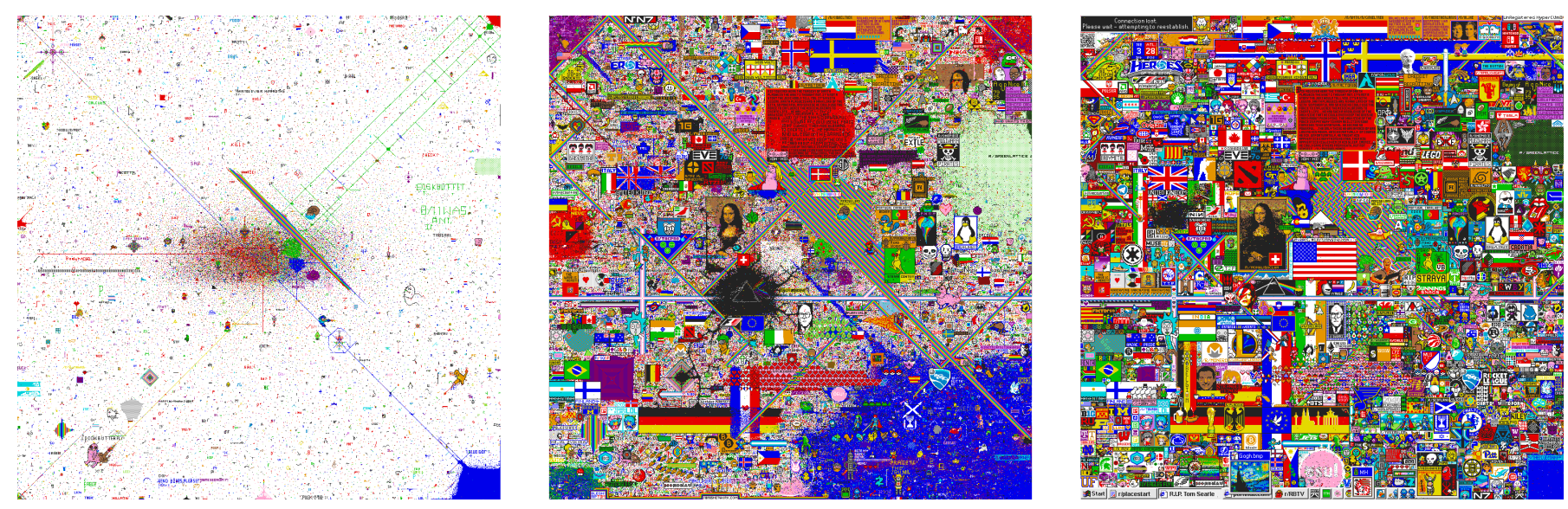

(b) Snapshots of Reddit's r/place canvas from beginning to end. Reconstructed from Albini's Archive [3].

Figure 4: Social dialogue genre examples.

and exhibited. For example, drawing on Dewey's notion that "[...] art is complete only as it works in the experience of others than the one who created it." [33], we could say that interactive artists could opt to give away control of their creation to allow other people to "complete" their work by experimenting with it, similar to what Eco [41] has called "the open work", later in 1967. This experience-focused approach supported by evaluation methods may allow not only the discovery of new knowledge on engagement and UX but also the creation of new artworks altogether.

It is our understanding that the cross-pollination between the arts and HCI can be explored as a two-way process. As HCI tends to move towards undetermined purposes and uncontrollable settings, and as art intends to explore the constraints and implications of computational media, which still demands the specialized technical skills of programming and testing, it is possible to envision space for mutual contribution between the fields. Even though HCI researchers and practitioners have had decades to propose, design, study and put into practice a wide range of evaluation methods, the use of these methods in different artistic contexts, and with unorthodox objectives, has the potential of shedding light on aspects not yet considered, possibly further improving such evaluation methods and contributing to HCI research.

In the following subsections, we present some examples of design and evaluation frameworks in Interactive Art. They are illustrative of evaluative practices of interactive systems, mostly developed in the realm of the arts. A larger and more comprehensive set of examples can be explored in [20]. Afterwards, we briefly discuss the use of participatory approaches to the design of Interactive Art.

\section{A. Candy's Model}

Candy [16], [17] proposes a generalized design and evaluation model which aims to support higher-level problem clarification regarding the development of Interactive Art. Candy's evaluation model is designed to clarify the elements of a design and/or evaluative process and the features to be designed and/or evaluated, along with applicable criteria, qualities or values. It includes four categories, which are: (1) Participants (people, creators); (2) Experience (process, interactions); (3) Outcomes (products); and (4) Environment (context). It may be summarized as follows:

1) Participants: it may include artists, technologists, audience, curators, organizers or even funding agencies; which may lead to the evaluation of features such 
as imagination, expertise, skill, experience, intention, reputation, success or failure; with criteria considering levels or degree of motivation, skill, education, expertise, engagement, curiosity, commitment or resources.

2) Experience: may encompass audience engagement, art practice, curatorship or system development; which may lead to the evaluation of features such as response, attitudes, risk-taking, interaction, innovation, design quality or performance; with criteria considering levels or degree of the experience being positive, negative, opportunistic, adventurous, curious, cautious, experienced or transcendent.

3) Outcomes: may include artworks, installations, exhibitions, performances or compositions; which may lead to the evaluation of features such as novelty, originality, impact, adaptability, aesthetics, effectiveness or appropriateness; with criteria considering levels or degree of qualities such as leading-edge, engaging, purposeful, enhancing, exciting or disturbing.

4) Environment: may comprise a studio, laboratory, museum, gallery or public space; which may lead to the evaluation of features such as physical spaces, facilities, costs, time, resources, effort, constraints or support; with criteria considering levels or degree of qualities such as design quality, convincing, adaptable, effective, innovative, sufficient, sustained, damaging or copious.

Candy's model shows a heavy emphasis on knowing beforehand and planning for the different parts who influence or are influenced by the design or evaluative process. Even though it is exemplified with stakeholders or aspects that are historically not common in HCI (e.g., art practice, performances, and disturbing or damaging qualities), we believe that there is a common ground to be explored here, especially when research more aligned with third-wave HCI is concerned.

\section{B. Costello and Edmonds' Pleasure Framework}

Aiming at identifying what constitutes pleasure in what the authors refer to as "playful interaction", Costello and Edmonds' pleasure framework [27]-[29] is composed of thirteen categories of pleasure that can be experienced when interacting with Interactive Art. According to the authors, the framework can be used both to support the design, as well as to evaluate playful interactive experiences. The framework's categories, with some considerations of our own in parenthesis, are:

- Creation is the pleasure from being able to create and express yourself creatively, obtained from the aesthetic qualities of the creation or simply from being in control (for an artwork to excel in this category it seems plausible that it must not only be interactive, but also participatory, elevating the audience to the status of co-authorship).

- Exploration is the pleasure of exploring something or an unfamiliar situation. It is often linked with Discovery, but sometimes it may also be self-contained.

- Discovery is the pleasure obtained from making a discovery, like discovering relationships between performed actions and respective responses from an artwork or even finding a solution to a problem (the amount of pleasure for finding a solution to a problem seems correlated with the next pleasure category: Difficulty).

- Difficulty is the pleasure from developing or exercising a physical or intellectual skill to do or achieve something, as an activity may often be more fun if it is not too easy (there may, however, be a fine line between achieving this pleasure and being frustrated with a too high difficulty).

- Competition is the pleasure of achieving a system or selfdefined goal. This goal may or may not involve working with or against another physical or virtual entity (when Competition is between people and not a virtual entity, it may be even a harder task to adjust Difficulty without frustrating one or both competitors, as Difficulty cannot be explicitly controlled anymore).

- Danger is the pleasure from feeling scared, in danger or as taking a risk. This feeling may vary between simply feeling a mild sense of unease, to a strong feeling of fear, and may occur indirectly through empathy for another entity, e.g., a fictional character.

- Captivation is the pleasure from feeling mesmerized, like being in some way controlled by another entity. It may happen, for instance, through an immersive experience that leaves the audience unconscious of its surroundings.

- Sensation is the pleasure from feeling a sensory physical action, e.g., touch, hearing etc. (besides a category on its own, the multisensory nature of Sensation leads us to think of it as also an underlying aspect of the other categories, as our senses are directly related to them).

- Sympathy is the pleasure from sharing physical or emotional feelings (as we understand, Sympathy is inherently reciprocal, as sharing feelings in the terms of simply exposing them may not be enough to achieve pleasure from this category. Reciprocity seems to be essential).

- Simulation is the pleasure from perceiving a copy or representation of something from real life (in our understanding, the Simulation category may not be limited to representations from the real, physical world; a physical or virtual representation of something virtual may also invoke the described pleasure).

- Fantasy is the pleasure from perceiving a fantastical creation of the human imagination, like the representation of peculiar fictional worlds and creatures.

- Camaraderie is the pleasure from developing a sense of friendship, fellowship or intimacy with someone (this category seems highly likely to be linked with Competition and Sympathy, and it seems fundamental to achieve behaviors of collaboration and self-organization).

- Subversion is the pleasure from breaking rules, subverting the meaning of something or watch someone else do it (in doing something not allowed or predicted by the system, this category may be linked with Exploration, Discovery, and Creation, as well as Danger in some circumstances).

According to Costello and Edmonds, it is not feasible for an interactive artwork to excel in all categories they propose 
simultaneously. This should not be the goal or the purpose of the framework altogether. The authors are more concerned with surfacing and understanding possible aspects of playful interaction that may or may not lead to some form of pleasure for people interacting with an artifact, as well as identifying which categories stand out in an artwork.

In contrast with Candy's model, which is more generalized and concerned with planning, Costello and Edmonds' pleasure framework is much more concerned about the very specific and complex qualities of playful interaction. Although the design of "pleasurable" user interfaces can be argued as a goal of UX design, we believe that the depth to which Costello and Edmonds explore the subject makes it a promising tool to be used by HCI researchers and practitioners, especially regarding categories of pleasure that traditionally can be considered unconventional (if not completely undesired) in traditional interaction design, such as difficulty, danger or subversion, with the exception of digital games design.

\section{Participatory Approaches}

The use of participatory approaches in the design of Interactive Art or installations has been reported in the scientific literature for over fifteen years. Frecon et al. [56], for instance, reported on how a museum installation about visualizing sound perception in submarines was redesigned with participatory activities to collect design suggestions with invited stakeholders. There is a significant amount of publications in the literature that present interactive installations designed with some kind of participatory design approach (e.g., [12], [31], [79], [86]). However, these studies tend to have their contributions oriented towards showing the created product qualities, while details of the design process are often absent or briefly discussed.

For studies that do give greater emphasis to the design process, many of those highlight the use of participatory approaches in early design phases to generate ideas and concepts. Some studies present the benefits of conducting fieldwork at the intended environment for an interactive artifact or installation [22], [24]. Some studies present a variety of early phase approaches to design, such as a rapid ethnographic study in a museum setting [81], integrating stakeholders into the design team to open-endedly generate design ideas, or developing early prototypes to gather feedback from users to lead the design from there [23], [65], and showing the feasibility of including children in the process to generate ideas for a virtual reality exhibit [87]. In a more holistic approach, Ciolfi et al. [25] describe a co-design process that iterates phases for the generation of new concepts (divergent activities) with phases for the selection of concepts to pursue (convergent activities). The authors describe the use of practical, embodied activities such as sketching in hardware, in-situ scenario building, bodystorming and combining technology and content.

Perhaps the most controversial aspect of it, participatory approaches may challenge traditional understandings of the concept of authorship, leading to the concept of co-authorship of Interactive Art. Jacucci et al. [63], for instance, compare the dichotomy between designer and users in HCI to artist and audience in artworks. It is argued that the growing interest in participatory approaches to both art and design can blur these dichotomies. Artists may invite people to contribute within a given conceptual framework, or they may encourage the artwork to be ultimately appropriated and extended by the joint participation of audience and artist.

\section{Discussion}

Because evaluation is a central aspect of $\mathrm{HCI}$, there is already a vast amount of knowledge on the subject in the literature and among HCI researchers and practitioners. Nevertheless, the HCI community could always benefit from novel perspectives on the subject. On the other hand, there is a growing interest from Interactive Art practitioners in evaluating their work. This apparent alignment of interests may allow the evaluation to serve as a common ground for collaboration between the fields. Classical HCI evaluation methods, however, do not seem to be useful, neither well accepted, in the context of art. Their focus on well-defined goals and objective metrics seems indeed out of place in the evaluation of Interactive Art, which is noticeable as both presented frameworks are heavily focused on experience. In contrast, evaluation methods focused on aspects of UX and aligned with third-wave HCI methods are already being appropriated by artists and used with relative success in some contexts, such as the evaluation of audience interaction with a collaborative interactive music system [10]; evaluation in public art, including planning, preparation and different points of view by different stakeholders [2]; and evaluation in the collaborative creation of a public digital media exhibition [8]. How artists may appropriate, apply and evolve these methods is of high interest of HCI research as well, as it brings novel approaches and different views the $\mathrm{HCI}$ community alone could not be able to devise or envision.

Candy's model, for instance, seems aligned with problem clarification methods that already inhabit HCI research for quite some time. As an example, Organisational Semiotics' Problem Articulation Methods (PAM), commonly used within Baranauskas' Socially Aware Computing (SAC) approach [5], similarly makes use of specific artifacts to elucidate problems. With proper epistemological and methodological considerations, an articulation of these two approaches may yield novel insights into projects with or without artistic intent. This line of inquiry, however, may also lead to a possible conflict between the traditional individualism of the creative process in art against the participatory nature of the SAC approach, i.e., authorship vs. co-authorship.

Costello and Edmonds' pleasure framework, in turn, could benefit from the Pleasure, Arousal, Dominance (PAD) emotional state model used in HCI practices. The pleasure framework's categories seem to be associated with the pleasure dimension in the PAD model; it also seems to encompass the arousal dimension, as the authors argue that some aspects of arousal act as modifying variables to the categories. This alignment with the PAD model may, perhaps, allow the use of 
well-established evaluation instruments alongside the framework, such as the Self-Assessment Manikin (SAM) [13]. Also, understanding the role of pleasure in interaction design may be an important tool for encouraging engagement, collaboration, and other desired aspects in projects with or without artistic intent. For that, the study of Tan and Ferguson [89] on the role of emotions in art evaluation may also provide further insights. Furthermore, some categories from the pleasure framework may be correlated with aspects already familiar to some HCI researchers. For instance: certain levels of creation can be considered to elevate the audience to the status of coauthorship, resembling aspects of Participatory Design; the amount of pleasure from difficulty can be analyzed from a perspective that combines the often fragile balance between motivation and ability; competition and sympathy may both involve and shape cultural aspects and values from the people involved; sensation can be explored from a Universal Design perspective; and simulation has much potential in the field of virtual reality.

We have already explored Costello and Edmonds' pleasure framework in the contexts of HCI computer science and computer engineering undergraduate and graduate courses [37], [39]. In these courses, we experimented with the approach of inserting art as a context for the discipline's main project. As preliminary results, students expanded their understanding of art and HCI and explored novel forms of interaction by creating projects around the concept of Interactive Art or installations. Students were also able to make sense of Costello and Edmonds' pleasure framework while they used it to evaluate projects from colleagues in a peer review manner and to inform the design of their projects. To further report these case studies is beyond the scope of this article, but it shows both applicability of the framework and how the classroom may be a useful medium to promote the articulation of art and science, reaching not only the HCI community but perhaps widely and openly Computer Science itself.

Lastly, we did not find in the literature efforts in Interactive Art design and evaluation that emphasize accessibility or Universal Design. This seems to be a missed opportunity as Interactive Art has an excellent potential for multisensory approaches (i.e., unlike a painting or a sculpture you are not allowed to touch, Interactive Art can be designed to not rely too heavily on sight by, for instance, also promoting other senses such as touch and hearing.) Some of the projects we designed and built with undergraduate and graduate $\mathrm{HCI}$ students already have higher attention to accessibility, but this remains an open opportunity for research. Furthermore, another possible direction to explore the subject of evaluation at the intersection between art and HCI is to revisit the practices of art critique and curatorship, which are usually not conducted by the artist itself, from an HCI perspective.

\section{A. Towards a Research Agenda}

Informed by what we presented and discussed so far in this article, we consider the following recommendations as essential steps towards articulating art and science in HCI through the concept of Interactive Art:

1) Encourage Interactive Art Research: There seems to be a steady increase in publications relative to the intersection between Interactive Art and HCI. However, there will always be numerous unexplored possibilities, and the potential mutual benefit for art and science seems to be a motivation to encourage further research on the subject. HCI communities could benefit from being open to works that permeate this frontier between the fields. Even though this could incur in some controversies regarding what is a valid scientific contribution in HCI (from conflicting ontological perspectives to different forms of rhetoric), these discussions could play an important role in contributing to the maturity of communities and openness to new ideas.

2) Study Interactive Art Examples: There are many Interactive Art approaches to be found in scientific literature and other sources from digital games to online communities, and this article only scratches the surface in this regard. Sometimes these artworks are not even intentionally designed as or named Interactive Art by their authors, but the lack of artistic intent does not prevent them from being perceived as art. Nevertheless, Interactive Art examples can provide useful insights that can inform the design of digital artifacts with or without artistic intent. Our examples of Interactive Art, for instance, show a varied collection of interaction approaches and desired qualities for interactive systems that, with proper study, may also be achieved to some degree in non-artistic contexts. The embodied ways in which we can interact with art, for instance, can be applied to the design of IoT systems for smart homes and other environments that go beyond a dashboard controlled from a smartphone, detecting and responding to our physical presence and actions.

3) Practice Interactive Art Design and Evaluation: Theory on Interactive Art cannot be considered complete without practice, and it is the very practice of Interactive Art that resonates well with the field of $\mathrm{HCI}$, providing a mutual benefit relationship. Furthermore, Cressey [30] argues that we are entering the "age of the arduino", supported by data on how such devices are transforming science regarding automation and data collection. Besides their low cost, these devices are relatively simple, allowing its use by people without expertise on the subject, i.e., there is no need to be an engineer or a computer scientist to use them successfully. Therefore, Arduino boards and the Raspberry Pi can serve as an inexpensive technical playground for people to explore interactive possibilities, whether they may be called Interactive Art or not. By exploring these technologies with a playful attitude, one can emerge significant learning experience and useful insights that could otherwise not be attained. Evaluation, in turn, complements the practice of Interactive Art with direct contributions to both Interactive Art practitioners and HCI researchers, serving as a common ground between the fields. The extensive evaluation knowledge from HCI can be borrowed, employed and deconstructed by interactive artists, which in turn can contribute to unconventional insights 
and approaches to evaluation. One possible way to foster the practice of Interactive Art design and evaluation is to conduct design projects about the subject in undergraduate and graduate HCI classes, such as the InterArt [37] and InstInt [39] projects we have already conducted and reported on.

4) Design Interactive Art for All: People should be able to experience Interactive Art regardless of their age, size, ability or disability. The open-ended nature of Interactive Art can be explored to push the boundaries of our understanding of accessibility and universal design both in terms of social critique, as well as in making use of multisensory approaches with different technologies of sensors and actuators. Tactile and sound feedback, for instance, can be used to not only complement visual features but also to open entirely new ways and possibilities to experience Interactive Art artifacts altogether, artifacts, in turn, that can be experienced to the greatest extent possible of people. The design of Interactive Art for all can be approached both from "bottom-up" or "topdown" perspectives: you can make universal design a goal from the start, and conduct every design activity with universal access in mind, or, by exploring current technologies and prototypes, you may obtain insights about how these can be used to allow people with some limitation or disability to have a better experience.

\section{CONCLUSION}

The articulation of art and science can be an important source of innovation in the domain of interactive systems, and HCI can have a mutual benefit relationship with art through Interactive Art. Looking back at our first research question, Interactive Art can be considered a source of innovation regarding unconventional forms of interacting with a computer. We highlighted four distinct interaction approaches found in Interactive Art in the literature and other sources. These have stressed virtual, embodied, tangible and social forms of interaction, and are illustrated with examples that contain useful qualities that may also be desired in computational systems without artistic intent.

For our second research question, evaluation can be used as a common ground between HCI and Interactive Art researchers and practitioners. There are useful frameworks in the literature to support the design and evaluation of Interactive Art, such as Candy's and Costello and Edmonds'. Although it is plausible that these could also be used in other contexts without artistic intent, there is still room for studies mixing them to some HCI practiced methods. Participatory approaches also provide unique ways of designing Interactive Art, providing a different perspective on the participatory design itself. It is noticeable how the potential issues raised by a combination of theory and practice on both art and technology design can have on reflection about political and social issues related to our being in the contemporary society.

The discussion on the results of the research questions addressed in this work leads to encouraging Interactive Art research, studying Interactive Art examples, practicing Inter- active Art design and evaluation, and designing Interactive Art for all, as essential starting points in a research agenda.

Ongoing work involves the articulation of art and science in HCI by following the research agenda we outlined. More specifically, we are conducting work on the design of Interactive Art in a socially aware manner [5], and with a coupled relation between body and environment as described in the Enactive approach by Varela, Rosch and Thompson [91]. We expect this articulation to lead us towards the conception of what we may call socioenactive Interactive Art.

\section{ACKNOWLEDGMENTS}

This study was financially supported by the National Council for Scientific and Technological Development (CNPq) through grant \#306272/2017-2 and by the São Paulo Research Foundation through grants \#2015/16528-0, \#2015/24300-9 and \#2017/06762-0. This article is an extended version of work published in [38].

\section{REFERENCES}

[1] P. D. Adamczyk, K. Hamilton, M. B. Twidale, and B. P. Bailey, "HCI and new media arts: Methodology and evaluation," in $\mathrm{CHI}$ '07 Extended Abstracts on Human Factors in Computing Systems, ser. CHI EA '07. New York, NY, USA: ACM, 2007, pp. 2813-2816. [Online]. Available: http://doi.acm.org/10.1145/1240866.1241084

[2] X. Alarcón-Díaz, K. Askaroff, L. Candy, E. A. Edmonds, J. Faram, and G. Hobson, "Evaluation in public art: The light logic exhibition,' in Interactive Experience in the Digital Age: Evaluating New Art Practice, L. Candy and S. Ferguson, Eds. Cham: Springer International Publishing, 2014, pp. 187-208. [Online]. Available: http://dx.doi.org/10.1007/978-3-319-04510-8_13

[3] P. Albini, "Archive of reddit's r/place," https://github.com/pietroalbini/reddit-place-2017, GitHub, April 2017.

[4] L. J. Bannon and P. Ehn, "Design: Design matters in participatory design," in Routledge International Handbook of Participatory Design, ser. Routledge International Handbooks, J. Simonsen and T. Robertson, Eds. London, United Kingdom: Routledge, 2013.

[5] M. C. C. Baranauskas, "Social awareness in HCI," interactions, vol. 21, no. 4, pp. 66-69, Jul. 2014. [Online]. Available: http: //doi.acm.org/10.1145/2621933

[6] J. Bardzell and S. Bardzell, "Humanistic hci," Synthesis Lectures on Human-Centered Informatics, vol. 8, no. 4, pp. 1-185, 2015. [Online]. Available: http://dx.doi.org/10.2200/S00664ED1V01Y201508HCI031

[7] J. Bardzell, S. Bardzell, and L. Koefoed Hansen, "Immodest proposals: Research through design and knowledge," in Proceedings of the 33rd Annual ACM Conference on Human Factors in Computing Systems, ser. CHI '15. New York, NY, USA: ACM, 2015, pp. 2093-2102. [Online]. Available: http://doi.acm.org/10.1145/2702123.2702400

[8] S. Barrass and A. L. S. Laws, "Experience and evaluation in the collective creation of a public digital exhibition," in Interactive Experience in the Digital Age: Evaluating New Art Practice, L. Candy and S. Ferguson, Eds. Cham: Springer International Publishing, 2014, pp. 209-219. [Online]. Available: http://dx.doi.org/10.1007/978-3-319-04510-8_14

[9] S. Benford, C. Greenhalgh, G. Giannachi, B. Walker, J. Marshall, and T. Rodden, "Uncomfortable user experience," Commun. ACM, vol. 56, no. 9, pp. 66-73, Sep. 2013. [Online]. Available: http: //doi.acm.org/10.1145/2500468.2500889

[10] B. Bengler and N. Bryan-Kinns, "In the wild: Evaluating collaborative interactive musical experiences in public settings," in Interactive Experience in the Digital Age: Evaluating New Art Practice, L. Candy and S. Ferguson, Eds. Cham: Springer International Publishing, 2014, pp. 169-186. [Online]. Available: http://dx.doi.org/10.1007/ 978-3-319-04510-8_12

[11] S. Bødker, "A human activity approach to user interfaces," Hum.Comput. Interact., vol. 4, no. 3, pp. 171-195, Sep. 1989. [Online]. Available: http://dx.doi.org/10.1207/s15327051hci0403_1 
[12] J. Bowers, L. Bannon, M. Fraser, J. Hindmarsh, S. Benford, C. Heath, G. Taxén, and L. Ciolfi, "From the disappearing computer to living exhibitions: Shaping interactivity in museum settings," in The Disappearing Computer: Interaction Design, System Infrastructures and Applications for Smart Environments, N. Streitz, A. Kameas, and I. Mavrommati, Eds. Berlin, Heidelberg: Springer Berlin Heidelberg, 2007, pp. 30-49. [Online]. Available: https: //doi.org/10.1007/978-3-540-72727-9_2

[13] M. M. Bradley and P. J. Lang, "Measuring emotion: the self-assessment manikin and the semantic differential," Journal of behavior therapy and experimental psychiatry, vol. 25, no. 1, pp. 49-59, 1994.

[14] R. Brown, "Imorphia: An embodied performance system," in Proceedings of the $2016 \mathrm{CHI}$ Conference Extended Abstracts on Human Factors in Computing Systems, ser. CHI EA '16. New York, NY, USA: ACM, 2016, pp. 3820-3823. [Online]. Available: http://doi.acm.org/10.1145/2851581.2891087

[15] A. Camci, "Distractions: Interactive visualizations on a kinetic sculpture using infrasound vibrations," in Proceedings of the 2016 CHI Conference Extended Abstracts on Human Factors in Computing Systems, ser. CHI EA '16. New York, NY, USA: ACM, 2016, pp. 3827-3830. [Online] Available: http://doi.acm.org/10.1145/2851581.2891104

[16] L. Candy, "Evaluating Creativity," in Creativity and Rationale: Enhancing Human Experience by Design, ser. Human-Computer Interaction Series, J. M. Carroll, Ed. London: Springer London, 2013, pp. 57-84. [Online]. Available: https://doi.org/10.1007/978-1-4471-4111-2_4

[17] _ "Evaluation and experience in art," in Interactive Experience in the Digital Age: Evaluating New Art Practice, L. Candy and S. Ferguson, Eds. Cham: Springer International Publishing, 2014, pp. 25-48. [Online]. Available: http://dx.doi.org/10.1007/978-3-319-04510-8 3

[18] L. Candy and E. Edmonds, "Introducing creativity to cognition," in Proceedings of the 3rd Conference on Creativity \& Cognition, ser C\&C '99. New York, NY, USA: ACM, 1999, pp. 3-6. [Online] Available: http://doi.acm.org/10.1145/317561.317562

[19] —- Explorations in Art and Technology, ser. Human-Computer Interaction Series. London: Springer-Verlag London Ltd., 2002. [Online]. Available: https://doi.org/10.1007/978-1-4471-4111-2_4

[20] L. Candy and S. Ferguson, Eds., Interactive Experience in the Digital Age: Evaluating New Art Practice, ser. Springer Series on Cultural Computing. Springer International Publishing, 2014. [Online]. Available: //www.springer.com/gp/book/9783319045092

[21] S. K. Card, A. Newell, and T. P. Moran, The Psychology of HumanComputer Interaction. Hillsdale, NJ, USA: L. Erlbaum Associates Inc., 1983.

[22] L. Ciolfi, M. Fernstrom, L. J. Bannon, P. Deshpande, P. Gallagher, C. McGettrick, N. Quinn, and S. Shirley, "The shannon portal installation: Interaction design for public places," Computer, vol. 40, no. 7, pp. 64-71, July 2007. [Online]. Available: http://dx.doi.org/10. 1109/MC.2007.255

[23] L. Ciolfi, G. Avram, L. Maye, N. Dulake, M. T. Marshall, D. van Dijk, and F. McDermott, "Articulating co-design in museums: Reflections on two participatory processes," in Proceedings of the 19th ACM Conference on Computer-Supported Cooperative Work \& Social Computing, ser. CSCW '16. New York, NY, USA: ACM, 2016, pp. 1325. [Online]. Available: http://doi.acm.org/10.1145/2818048.2819967

[24] L. Ciolfi and D. Petrelli, "Studying a community of volunteers at a historic cemetery to inspire interaction concepts," in Proceedings of the 7th International Conference on Communities and Technologies, ser C\&T '15. New York, NY, USA: ACM, 2015, pp. 139-148. [Online]. Available: http://doi.acm.org/10.1145/2768545.2768547

[25] L. Ciolfi, D. Petrelli, F. McDermott, G. Avram, and D. van Dijk, "Co-design to empower cultural heritage professionals as technology designers," in Empowering Users through Design: Interdisciplinary Studies and Combined Approaches for Technological Products and Services, D. Bihanic, Ed. Cham: Springer International Publishing, 2015, pp. 213-224. [Online]. Available: https://doi. org/10.1007/978-3-319-13018-7_12

[26] R. E. Clarke, J. Briggs, A. Light, S. Heitlinger, and C. Crivellaro, "Socially engaged arts practice in hci," in CHI '14 Extended Abstracts on Human Factors in Computing Systems, ser. CHI EA '14. New York, NY, USA: ACM, 2014, pp. 69-74. [Online]. Available: http://doi.acm.org/10.1145/2559206.2559227

[27] B. Costello, "A pleasure framework," Leonardo, vol. 40, no. 4, pp. 370-371, July 2007. [Online]. Available: http://dx.doi.org/10.1162/leon. 2007.40.4.370
[28] B. Costello and E. A. Edmonds, "A study in play, pleasure and interaction design," in Proceedings of the 2007 Conference on Designing Pleasurable Products and Interfaces, ser. DPPI '07. New York, NY, USA: ACM, 2007, pp. 76-91. [Online]. Available: http://doi.acm.org/10.1145/1314161.1314168

[29] _ _ "A tool for characterizing the experience of play," in Proceedings of the Sixth Australasian Conference on Interactive Entertainment, ser IE '09. New York, NY, USA: ACM, 2009, pp. 2:1-2:10. [Online]. Available: http://doi.acm.org/10.1145/1746050.1746052

[30] D. Cressey, "Age of the arduino," Nature, vol. 544, no. 7648, pp. 125126, April 2017.

[31] P. Dalsgård and K. Halskov, "Real life experiences with experience design," in Proceedings of the 4th Nordic Conference on Humancomputer Interaction: Changing Roles, ser. NordiCHI '06. New York, NY, USA: ACM, 2006, pp. 331-340. [Online]. Available: http://doi.acm.org/10.1145/1182475.1182510

[32] A. Daniele, "This is not private," in Proceedings of the 2016 CHI Conference Extended Abstracts on Human Factors in Computing Systems, ser. CHI EA '16. New York, NY, USA: ACM, 2016, pp. 38313834. [Online]. Available: http://doi.acm.org/10.1145/2851581.2891086

[33] J. Dewey, Art as Experience. New York, NY, USA: Minton, Balch \& Company, 1934.

[34] D. Domingues, C. J. Miosso, S. F. Rodrigues, C. S. R. Aguiar, T. F. Lucena, M. Miranda, A. F. Rocha, and R. Raskar, "Embodiments, visualizations, and immersion with enactive affective systems," in Proc. SPIE, vol. 9012, 2014, pp. $90120 \mathrm{~J}-90$ 120J-13. [Online]. Available: http://dx.doi.org/10.1117/12.2042590

[35] J. Doyle and N. Hieda, "Avian attractor," in Proceedings of the 2016 CHI Conference Extended Abstracts on Human Factors in Computing Systems, ser. CHI EA '16. New York, NY, USA: ACM, 2016, pp. 38353838. [Online]. Available: http://doi.acm.org/10.1145/2851581.2891093

[36] E. F. Duarte and M. C. C. Baranauskas, "Revisiting the three HCI waves: A preliminary discussion on philosophy of science and research paradigms," in Proceedings of the 15th Brazilian Symposium on Human Factors in Computer Systems, ser. IHC '16. New York, NY, USA: ACM, 2016, pp. 38:1-38:4. [Online]. Available: http://doi.acm.org/10.1145/3033701.3033740

[37] —, "Interart: Learning human-computer interaction through the making of interactive art," in Human-Computer Interaction. Theories, Methods, and Human Issues, M. Kurosu, Ed. Cham: Springer International Publishing, 2018, pp. 35-54. [Online]. Available: https://doi.org/10.1007/978-3-319-91238-7_4

[38] _ - "Revisiting interactive art from an interaction design perspective: Opening a research agenda," in Proceedings of the 17th Brazilian Symposium on Human Factors in Computing Systems, ser. IHC 2018. New York, NY, USA: ACM, 2018, pp. 35:1-35:10. [Online]. Available: http://doi.acm.org/10.1145/3274192.3274227

[39] E. F. Duarte, F. M. Gonçalves, and M. C. C. Baranauskas, "Instint: Enacting a small-scale interactive installation through co-design," in Proceedings of the 30th Australian Conference on Computer-Human Interaction, ser. OzCHI '18. New York, NY, USA: ACM, 2018, pp. 338-348. [Online]. Available: http: //doi.acm.org/10.1145/3292147.3292158

[40] A. Dunne and F. Raby, Speculative Everything: Design, Fiction, and Social Dreaming, ser. The MIT Press. MIT Press, 2013.

[41] U. Eco, The open work. Harvard Univerisity Press, 1989.

[42] E. Edmonds, "The art of interaction: What hci can learn from interactive art," Synthesis Lectures on Human-Centered Informatics, vol. 11, no. 1, pp. i-73, 2018. [Online]. Available: https://doi.org/10. 2200/S00825ED1V01Y201802HCI039

[43] E. Edmonds, S. Benford, Z. Bilda, J. Fantauzzacoffin, R. Malina, and H. Vinet, "Digital arts: Did you feel that?" in CHI '13 Extended Abstracts on Human Factors in Computing Systems, ser. CHI EA '13. New York, NY, USA: ACM, 2013, pp. 2439-2446. [Online]. Available: http://doi.acm.org/10.1145/2468356.2468797

[44] E. Edmonds and S. Clark, "Tango apart: Moving together," in Proceedings of the 2016 CHI Conference Extended Abstracts on Human Factors in Computing Systems, ser. CHI EA '16. New York, NY, USA: ACM, 2016, pp. 3663-3666. [Online]. Available: http://doi.acm.org/10.1145/2851581.2890235 
[45] E. A. Edmonds, "Human computer interaction, art and experience," in Interactive Experience in the Digital Age: Evaluating New Art Practice, L. Candy and S. Ferguson, Eds. Cham: Springer International Publishing, 2014, pp. 11-23. [Online]. Available: http://dx.doi.org/10.1007/978-3-319-04510-8_2

[46] D. C. Engelbart, "Augmenting human intellect: A conceptual framework," Stanford Research Institute, Tech. Rep., 1962. [Online]. Available: https://www.dougengelbart.org/pubs/augment-3906.html

[47] D. England, "Art.chi: Curating the digital," in Curating the Digital: Space for Art and Interaction, D. England, T. Schiphorst, and N. BryanKinns, Eds. Cham: Springer International Publishing, 2016, pp. 1-7. [Online]. Available: http://dx.doi.org/10.1007/978-3-319-28722-5_1

[48] D. England, L. Candy, C. Latulipe, T. Schiphorst, E. Edmonds, Y. Kim, S. Clark, and A. Kerne, "Art.chi," in Proceedings of the 33rd Annual ACM Conference Extended Abstracts on Human Factors in Computing Systems, ser. CHI EA '15. New York, NY, USA: ACM, 2015, pp. 23292332. [Online]. Available: http://doi.acm.org/10.1145/2702613.2702637

[49] D. England, E. Edmonds, J. G. Sheridan, S. Pobiner, N. BryanKinns, P. Wright, M. Twidale, and C. Diana, "Digital arts and interaction (invited)," in CHI '11 Extended Abstracts on Human Factors in Computing Systems, ser. CHI EA '11. New York, NY, USA: ACM, 2011, pp. 609-612. [Online]. Available: http://doi.acm.org/10.1145/1979742.1979538

[50] D. England, C. Latulipe, N. Bryan-Kinns, E. Edmonds, and S. Clark, "Art.chi ii: Digital art in a post-digital world," in Proceedings of the 2016 CHI Conference Extended Abstracts on Human Factors in Computing Systems, ser. CHI EA '16. New York, NY, USA: ACM, 2016, pp. 3477-3483. [Online]. Available: http://doi.acm.org/10.1145/2851581.2856474

[51] D. England, J. C. Spence, C. E. Latulipe, E. A. Edmonds, L. Candy, T. Schiphorst, N. Bryan-Kinns, and K. Woolford, "Art and interaction sig: Cataloging the digital arts," in Proceedings of the Extended Abstracts of the 32Nd Annual ACM Conference on Human Factors in Computing Systems, ser. CHI EA '14. New York, NY, USA: ACM, 2014, pp. 1115-1118. [Online]. Available: http://doi.acm.org/10.1145/2559206.2559210

[52] J. Fantauzzacoffin, J. Berzowska, E. Edmonds, K. Goldberg, D. F. Harrell, and B. Smith, "The arts, HCI, and innovation policy discourse: Invited panel," in CHI '12 Extended Abstracts on Human Factors in Computing Systems, ser. CHI EA '12. New York, NY, USA: ACM, 2012, pp. 1111-1114. [Online]. Available: http://doi.acm.org/10.1145/2212776.2212399

[53] J. Fantauzzacoffin, L. Candy, A. Chenzira, E. Edmonds, D. England, T. Schiphorst, and A. Tanaka, "Articulating lines of research in digital arts, HCI, and interaction (invited sig)," in CHI '12 Extended Abstracts on Human Factors in Computing Systems, ser. CHI EA '12. New York, NY, USA: ACM, 2012, pp. 1177-1180. [Online]. Available: http://doi.acm.org/10.1145/2212776.2212417

[54] P. M. Fitts, "The information capacity of the human motor system in controlling the amplitude of movement." Journal of experimental psychology, vol. 47, no. 6, p. 381, 1954.

[55] C. Frayling, "Research in art and design," Royal College of Art Research Papers, vol. 1, no. 1, pp. 1-5, 1993. [Online]. Available: http://researchonline.rca.ac.uk/384/

[56] E. Frecon, O. Stahl, J. Soderberg, and A. Wallberg, "Visualising sound perception in a submarine: A museum installation," in Eighth IEEE International Symposium on Distributed Simulation and Real-Time Applications. Budapest, Hungary: IEEE, Oct 2004, pp. 38-45. [Online]. Available: http://dx.doi.org/10.1109/DS-RT.2004.43

[57] Game Freak, "Pokémon red," Game [Game Boy], Tokyo, Japan, September 1998, nintendo Co., Ltd., Kyoto, Japan.

[58] W. Gaver, "What should we expect from research through design?" in Proceedings of the SIGCHI Conference on Human Factors in Computing Systems, ser. CHI '12. New York, NY, USA: ACM, 2012, pp. 937-946. [Online]. Available: http://doi.acm.org/10.1145/2207676.2208538

[59] J. Grudin, "The computer reaches out: The historical continuity of interface design," in Proceedings of the SIGCHI Conference on Human Factors in Computing Systems, ser. CHI '90. New York, NY, USA: ACM, 1990, pp. 261-268. [Online]. Available: http://doi.acm.org/10.1145/97243.97284
[60] B. Ha, "Endless ripples: A growing interactive donation device," in Proceedings of the 2016 CHI Conference Extended Abstracts on Human Factors in Computing Systems, ser. CHI EA '16. New York, NY, USA: ACM, 2016, pp. 3843-3846. [Online]. Available: http://doi.acm.org/10.1145/2851581.2891103

[61] T. T. Hewett, R. Baecker, S. Card, T. Carey, J. Gasen, M. Mantei, G. Perlman, G. Strong, and W. Verplank, "Acm sigchi curricula for human-computer interaction," Association for Computing Machinery (ACM), New York, NY, USA, Tech. Rep., 1992.

[62] H. Ishii and B. Ullmer, "Tangible bits: Towards seamless interfaces between people, bits and atoms," in Proceedings of the ACM SIGCHI Conference on Human Factors in Computing Systems, ser. CHI ' 97. New York, NY, USA: ACM, 1997, pp. 234-241. [Online]. Available: http://doi.acm.org/10.1145/258549.258715

[63] G. Jacucci, M. Wagner, I. Wagner, E. Giaccardi, M. Annunziato, N. Breyer, J. Hansen, K. Jo, S. Ossevoort, A. Perini, N. Roussel, and S. Schuricht, "Participart: Exploring participation in interactive art installations," in 2010 IEEE International Symposium on Mixed and Augmented Reality - Arts, Media, and Humanities. Seoul, South Korea: IEEE, Oct 2010, pp. 3-10. [Online]. Available: http://dx.doi.org/10.1109/ISMAR-AMH.2010.5643313

[64] M. Jazbec and F. Erich, "Investigating human identity using the idmirror interactive installation," in Proceedings of the 2016 CHI Conference Extended Abstracts on Human Factors in Computing Systems, ser. CHI EA '16. New York, NY, USA: ACM, 2016, pp. 3851-3854. [Online]. Available: http://doi.acm.org/10.1145/2851581.2891091

[65] F. Jégou, "Co-design approaches for early phases of augmented environments," in Designing User Friendly Augmented Work Environments: From Meeting Rooms to Digital Collaborative Spaces, S. Lahlou, Ed. London: Springer London, 2009, pp. 159-189. [Online]. Available: https://doi.org/10.1007/978-1-84800-098-8_6

[66] M. Kaipainen, N. Ravaja, P. Tikka, R. Vuori, R. Pugliese, M. Rapino, and T. Takala, "Enactive systems and enactive media: Embodied human-machine coupling beyond interfaces," Leonardo, vol. 44, no. 5, pp. 433-438, September 2011. [Online]. Available: http://dx.doi.org/10.1162/LEON_a_00244

[67] L. L. Kang, "Breaking andywall: Transgressive and playful exploration on the dynamic role of users in art and design," in Proceedings of the 2016 CHI Conference Extended Abstracts on Human Factors in Computing Systems, ser. CHI EA '16. New York, NY, USA: ACM, 2016, pp. 3855-3858. [Online]. Available: http: //doi.acm.org/10.1145/2851581.2891100

[68] G. P. Khut, "Designing biofeedback artworks for relaxation," in Proceedings of the 2016 CHI Conference Extended Abstracts on Human Factors in Computing Systems, ser. CHI EA '16. New York, NY, USA: ACM, 2016, pp. 3859-3862. [Online]. Available: http://doi.acm.org/10.1145/2851581.2891089

[69] H. Kobayashi, H. Kudo, V. Moulder, M. Heidt, and L. Boschman, "Fukushima audio census," in Proceedings of the 2017 CHI Conference Extended Abstracts on Human Factors in Computing Systems, ser. CHI EA '17. New York, NY, USA: ACM, 2017, pp. 1393-1398. [Online]. Available: http://doi.acm.org/10.1145/3027063.3052546

[70] V. Kostakos, "The big hole in HCI research," interactions, vol. 22, no. 2, pp. 48-51, Feb. 2015. [Online]. Available: http://doi.acm.org/10. $1145 / 2729103$

[71] M. W. Krueger, "Responsive environments," in Proceedings of the June 13-16, 1977, National Computer Conference, ser. AFIPS '77. New York, NY, USA: ACM, 1977, pp. 423-433. [Online]. Available: http://doi.acm.org/10.1145/1499402.1499476

[72] S. W. Lee and G. Essl, "Live writing: Gloomy streets," in Proceedings of the 2017 CHI Conference Extended Abstracts on Human Factors in Computing Systems, ser. CHI EA '17. New York, NY, USA: ACM, 2017, pp. 1387-1392. [Online]. Available: http://doi.acm.org/10.1145/3027063.3052545

[73] T. W. Leong, L. Gaye, A. Tanaka, R. Taylor, and P. C. Wright, "The user in flux: Bringing $\mathrm{HCI}$ and digital arts together to interrogate shifting roles in interactive media," in $\mathrm{CHI}$ ' 11 Extended Abstracts on Human Factors in Computing Systems, ser. CHI EA '11. New York, NY, USA: ACM, 2011, pp. 45-48. [Online]. Available: http://doi.acm.org/10.1145/1979742.1979571

[74] A. Machado, "Waldemar cordeiro: o brasileiro precursor da arte mediada por computadores," Revista Eco Pós, vol. 18, no. 1, pp. 25-35, 2015. [Online]. Available: https://revistas.ufrj.br/index.php/eco_ pos/article/view/2392 
[75] J. Maeda, "Artists and Scientists: More Alike Than Different," Jul. 2013. [Online]. Available: https://blogs.scientificamerican.com/ guest-blog/artists-and-scientists-more-alike-than-different/

[76] E. Mendelowitz, D. Seeley, and D. Glicksman, "Whorl: An immersive dive into a world of flowers, color, and play," in Proceedings of the 2016 CHI Conference Extended Abstracts on Human Factors in Computing Systems, ser. CHI EA '16. New York, NY, USA: ACM, 2016, pp. 38713874. [Online]. Available: http://doi.acm.org/10.1145/2851581.2891092

[77] G. Moscati, "Waldemar Cordeiro e o uso do computador nas artes - Um depoimento sobre uma experiência pioneira," Revista USP, no. 24, pp. 124-135, Feb. 1995. [Online]. Available: http: //www.journals.usp.br/revusp/article/view/27036

[78] L. Muller, E. Edmonds, and M. Connell, "Living laboratories for interactive art," CoDesign, vol. 2, no. 4, pp. 195-207, 2006. [Online] Available: http://dx.doi.org/10.1080/15710880601008109

[79] P. K. Nikolic, "Collective creativity: Utilizing the potentials of multimodal environments," in Internet of Things. IoT Infrastructures, R. Giaffreda, D. Cagáňová, Y. Li, R. Riggio, and A. Voisard, Eds. Cham: Springer International Publishing, 2015, pp. 27-37.

[80] D. A. Norman, The Design of Everyday Things. New York, NY: Doubleday/Currency, 1990.

[81] E. Patsoule, "Interactions around a multi-touch tabletop: A rapid ethnographic study in a museum," in Design, User Experience, and Usability. User Experience Design Practice, A. Marcus, Ed. Cham: Springer International Publishing, 2014, pp. 434-445.

[82] C. Pearce, G. Smith, J. Choi, and I. Carlsson, "ebee: Merging quilting, electronics \&\#38; board game design," in Proceedings of the 2016 CHI Conference Extended Abstracts on Human Factors in Computing Systems, ser. CHI EA '16. New York, NY, USA: ACM, 2016, pp. 38773880. [Online]. Available: http://doi.acm.org/10.1145/2851581.2891099

[83] I. Posch and E. Kurbak, "Crafted logic towards hand-crafting a computer," in Proceedings of the 2016 CHI Conference Extended Abstracts on Human Factors in Computing Systems, ser. CHI EA '16. New York, NY, USA: ACM, 2016, pp. 3881-3884. [Online]. Available: http://doi.acm.org/10.1145/2851581.2891101

[84] J. Seevinck, "Dichroic w." in Proceedings of the 2016 CHI Conference Extended Abstracts on Human Factors in Computing Systems, ser. CHI EA '16. New York, NY, USA: ACM, 2016, pp. 3889-3892. [Online]. Available: http://doi.acm.org/10.1145/2851581.2891094

[85] P. Sengers and C. Csikszentmihályi, "HCI and the arts: A conflicted convergence?" in CHI '03 Extended Abstracts on Human Factors in Computing Systems, ser. CHI EA '03. New York, NY, USA: ACM, 2003, pp. 876-877. [Online]. Available: http: //doi.acm.org/10.1145/765891.766044
[86] O. Shaer, C. Valdes, S. Liu, K. Lu, K. Chang, W. Xu, T. L. Haddock, S. Bhatia, D. Densmore, and R. Kincaid, "Designing reality-based interfaces for experiential bio-design," Personal and Ubiquitous Computing, vol. 18, no. 6, pp. 1515-1532, Aug 2014. [Online]. Available: https://doi.org/10.1007/s00779-013-0752-1

[87] G. Sim, B. Cassidy, and J. C. Read, "Crowdsourcing ideas for augmented reality museum experiences with children," in Museum Experience Design: Crowds, Ecosystems and Novel Technologies, A. Vermeeren, L. Calvi, and A. Sabiescu, Eds. Cham: Springer International Publishing, 2018, pp. 75-93. [Online]. Available: https://doi.org/10.1007/978-3-319-58550-5 4

[88] L. A. Suchman, Plans and Situated Actions: The Problem of Humanmachine Communication. New York, NY, USA: Cambridge University Press, 1987.

[89] C. T. Tan and S. Ferguson, "The role of emotions in art evaluation," in Interactive Experience in the Digital Age: Evaluating New Art Practice, L. Candy and S. Ferguson, Eds. Cham: Springer International Publishing, 2014, pp. 139-152. [Online]. Available: http://dx.doi.org/10.1007/978-3-319-04510-8_10

[90] thatgamecompany, "Journey," Game [Playstation 3], Los Angeles, USA 2012, sony Computer Entertainment Inc., Tokyo, Japan.

[91] F. J. Varela, E. Thompson, and E. Rosch, The Embodied Mind: Cognitive Science and Human Experience. Cambridge, MA, USA: MIT Press, 1991.

[92] V. Weiley and E. Edmonds, "The HCI researcher as artist and designer: Approaches to creativity and distance," in Proceedings of the 8th ACM Conference on Creativity and Cognition, ser. C\&C '11. New York, NY, USA: ACM, 2011, pp. 233-238. [Online]. Available: http://doi.acm.org/10.1145/2069618.2069658

[93] S. Wilson, "Art as research," 1996, available at: http://userwww.sfsu edu/swilson/papers/artist.researcher.html

[94] _ "Science and art - looking backward/looking forward," 2003 available at: http://www.artcenter.edu/williamson/neuro/exhibit/f_body_ wilson.html.

[95] T. Winograd and F. Flores, Eds., Understanding Computers and Cognition. Norwood, NJ, USA: Ablex Publishing Corp., 1985.

[96] J. Zimmerman, J. Forlizzi, and S. Evenson, "Research through design as a method for interaction design research in HCI," in Proceedings of the SIGCHI Conference on Human Factors in Computing Systems, ser. CHI '07. New York, NY, USA: ACM, 2007, pp. 493-502. [Online]. Available: http://doi.acm.org/10.1145/1240624.1240704 